\title{
Development of the Human Dentition
}

Author: Frans P. G. M. van der Linden

Publisher: Quintessence Publishing

Language: English

ISBN: 978-0-86715-725-3

Edition: 1/e

Publish Year: 2016

Pages: 240, illustrated

Price: $99.00 €$

Dr Frans P.G.M. van der Linden, Professor Emeritus in the Department of Orthodontics at Radboud University Nijmegen, Netherlands in his new book entitled "Development of the Human Dentition", presents the complexity of the development of dentition, deciduous and permanent.

The book is divided in 17 chapters. It starts with tooth formation, development of deciduous dentition, transitional period (first, inter, and second) and changeover to the permanent dentition.

After the general aspects on the development of the dentition on adults, it talks about the interactions between dentition, skeleton, and function. Only by understanding the normal development of the adult dentition can we understand abnormalities of the dental arches and orthodontic malocclusions. In the next following chapters the readers are provided with information about open bites, asymmetries, transverse deviations, forced bites and premature loss of deciduous teeth.

In the last chapter the author presents statistical data selected and compiled from the results of studies carried out mainly in Western countries.

The book entitled "Development of the Human Dentition" is an exceptional guide for all those who wish to deepen their knowledge on dentition development, dental occlusion and especially the effectiveness of complex orthodontic treatment.

DOI: 10.25241/stomaeduj.2017.4(3).bookreview.1

Marian-Vladimir Constantinescu

$\mathrm{DDS}, \mathrm{PhD}$ Holistic Dental \& Medical Institute of Bucharest-ROPOSTURO, Bucharest,

Romania
e-mail: dr.vladimir.constantinescu@gmail.com 